\title{
Inherited Thrombophilia and Recurrent Pregnancy Loss
}

\author{
Alireza Parand ${ }^{1,3}$, Jale Zolghadri ${ }^{2}$, Mozhgan Nezam ${ }^{2}$, Abdolreza Afrasiabi ${ }^{3}$, Sezaneh \\ Haghpanah $^{3}$, Mehran Karimi ${ }^{3,}$ \\ 1 Iranian Hospital, Dubai, UAE \\ ${ }^{2}$ Infertility Research Center, Gynecology and Obstetrics Department, Shiraz University of Medical Sciences, Shiraz, IR Iran \\ ${ }^{3}$ Hematology Research Center, Shiraz University of Medical Sciences, Shiraz, IR Iran \\ *Corresponding Author: Mehran Karimi, Hematology Research Center, Shiraz University of Medical Sciences, Namazi Hospital, Shiraz, IR Iran. Tel/Fax: +98-7116473239; 09171123975, \\ E-mail:karimim@sums.ac.ir.
}

Received: July 20, 2013; Revised: September 1, 2013; Accepted: November 12, 2013

\begin{abstract}
Background: Recurrent pregnancy loss (RPL) is a common health problem. The polymorphisms G20210A of prothrombin gene (FII G 20210A), and G 1691A of factor Vgene (FactorVLeiden, FVL)are the most extensively studied thrombophilic mutations regarding recurrent miscarriage (abortion).

Objectives: To determine the frequency of FII G20210A and FVL polymorphisms as well as protein C and protein S deficiency in a series of patients with RPL compared to control group.

Patients and Methods: The study group included 90 randomly selected patients with three or more consecutive miscarriages with the same partner in $<20$ weeks of gestational age in 2012. The control population consisted of 44 age-matched women with at least one live born children and no history of pregnancy loss. Functional activity of protein C and S, activated protein C resistance, FVL assay by polymerase chain reaction, and prothrombin gene mutation were assessed. The polymorphism frequencies were recorded for each group and comparisons were made.

Results: The mean functional activity of protein Cand protein $S$ were not significantly different between case and control groups $(\mathrm{P}>0.05)$. Frequency of protein $\mathrm{C}$ deficiency was also not significantly different between the case and control groups $(\mathrm{P}=0.906)$, but frequency of protein $\mathrm{S}$ deficiency was significantly higher in patients than controls $(\mathrm{P}=0.03)$. Genotype patterns of the patients and healthy individuals were not significantly different regarding either FVL or Prothrombin G20210A $(\mathrm{P}>0.05)$.

Conclusions: We determined a significant higher frequency of protein S deficiency in patients with RPL compared to controls. But the frequency of protein C deficiency and the two common thrombophilic mutations (Factor V Leiden and Prothrombin G20210A), were not significantly different between patients with recurrent miscarriage and healthy women.
\end{abstract}

Keywords: Inherited; Pregnancy loss; Thrombophilia

\section{Background}

Prothrombotic disorders have been associated with the pathophysiology of many obstetric complications of placental origin (e.g. stillbirth, fetal growth restriction, severe preeclampsia, and placental abruption), moreover congenital thrombophilia had inevitably drawn researchers interest for its potential role in recurrent miscarriage. Recurrent pregnancy loss (RPL) is a common health problem, with three or more loses affecting 1-2\%, and two or more losses affecting up to $5 \%$ of women at reproductive age $(1,2)$.

The polymorphisms G20210A of prothrombin gene (FII $G$ 20210A) and G 1691A of factor V gene (Factor V Leiden, $\mathrm{FVL}$ ) and C677T of methylene tetrahydrofolate reductase gene (MTHFR C677T) are the most extensively studied thrombophilic mutations regarding recurrent miscar- riage. It appears that the presence of FII G20210A and Factor V Leiden mutation increases the risk of recurrent early pregnancy loss (odds ratios 2.49 for FII G20210A, 2.71 for homozygous, and 1.68 for heterozygous FVL); whereas, homozygosity for MTHFR C677F does not significantly increase the risk (odds ratio 1.40, 95\% CI 0.77-2.55)(3).

The R2 haplotype of factor $\mathrm{V}$ is characterized by a mild reduction of total factor $\mathrm{V}$ levels, with a relative increase of the more thrombogenic isoform, FVL (4). The polymorphism Arg1299His (A 4070G) is one of the mutations resulting in the R2 haplotype, and its association with thrombotic events has been variable (5-7). In contrast to FVL, the presence of $\mathrm{A} 1299 \mathrm{H}$ does not appear to increase the risk of recurrent miscarriage.

A second common mutation for the MTHFR gene is produced by an A to C transition at nucleotide 1298 (A

Implication for health policy/practice/research/medical education:

We determined the frequency of FII G20210A and FVL polymorphisms as well as protein C and protein S deficiency in a series of patients with recurrent pregnancy loss compared to control group.

Copyright (C) 2013, Iranian Red Crescent Medical Journal; Published by Kowsar Corp. This is an open-access article distributed under the terms of the Creative Commons Attribution License, which permits unrestricted use, distribution, and reproduction in any medium, provided the original work is properly cited. 
1298C), leading to a glutamate to alanine substitution in the MTHFR protein, and resulting finally in a $40 \%$ reduction in the activity of the enzyme (8). In contrast to C 677T, where homozygosity (TT) results in a significant increase in total plasma homocysteine levels, homocysteine concentrations do not appear significantly elevated with the 1298CC genotype $(8,9)$. Although the presence of MTHFR mutations is significantly more common in miscarried embryos (10), current evidence has failed to support an association between these polymorphisms and increased risk of recurrent miscarriage (11-13). Deficiencies of the natural anticoagulant protein $\mathrm{C}, \mathrm{S}$ and antithrombin occur much less than $1 \%$ to $2 \%$ of the population. Anticoagulant protein deficiencies increased the risk of fetal loss in most, but not all of the limited number of studies.

The EPCOT study showed that the risk of stillbirth (but not miscarriage) is highest in women with combined thrombophilic defects (14). Inevitably, combination of even minor thrombophilic mutations has been studied regarding recurrent miscarriage, with heterogeneous and inconsistent results $(11,12,15)$.

\section{Objectives}

In the present study, we compared the frequency of FII G20210A and FVL polymorphisms in a series of patients with three or more consecutive miscarriages with control group. Also we compared activated protein $C$ resistance (APCR), protein $C$ and protein $S$ between the two groups.

\section{Patients and Methods}

\subsection{Patients and Controls}

In this case-control cross-sectional study, 90 patients with three or more consecutive miscarriages with the same partner in $<20$ weeks of gestational age were randomly selected. Considering a difference between ratio of $9 \%, \alpha=0.05$ and power $80 \%, 97$ patients were calculated in each group using Power SSC software. Due to low financial support, 45 were allocated to control group. One of the controls had missing data and was excluded from the study. Finally, we had 90 patients in the case group and 44 patients in the control group. All of them were investigated in the Homeostasis and Thrombosis Unit of Hematology Research Center, Shiraz, Southern Iran. The study was performed from April 2011 to April 2012. The study was approved by the local Ethics Committee of Shiraz University of Medical Sciences (Code: 2563, Date: March 2008). We considered patient privacy in all stages of our study. Three or more pregnancy loss was defined as RPL. We obtained medical histories, performed physical examinations, routine laboratory tests, fibrinogen level, endocrinologic examinations, 5 molar urea test for detection of factor XIII deficiency, and immunologic tests for autoantibodies in patients. Exclusion criteria were: anatomic abnormalities, endocrinologic and liver dysfunction, inflammatory pelvic disease, polycystic ovary syndrome, fibrinogen deficiency, antiphospholipid antibodies, and factor XIII deficiency. Seven patients were excluded from the study based on the mentioned criteria, and 90 patients were eligible for participation.

The control population consisted of 44 age-matched women, with at least one live born children and no history of pregnancy loss. These women were recruited during their attendance to the Gynecology Outpatient Clinic for a routine Pap smear. All participants were from the same ethnical background, and gave their informed consent before inclusion to the study. One observer evaluated all patients and controls for their participation in the study.

\subsection{Laboratory Evaluation}

Venipuncture was performed on day 8-10 of the menstrual cycle to examine thrombophilic factors. Venous blood was collected on $0.129 \mathrm{~mol} / \mathrm{L}$ trisodium citrate and was centrifuged twice at $2000 \mathrm{~g}$ for $15 \mathrm{~min}$ at room temperature to obtain plasma with relatively few remaining platelets. Plasma was then frozen and stored in small aliquots at $-70^{\circ} \mathrm{C}$ until tested. Ethylene diamineteraacetic acid (EDTA) anticoagulant samples were used for DNA analysis. EDTA blood was snap-frozen and immediately stored at $-70{ }^{\circ} \mathrm{C}$. Genomic DNA was prepared from blood samples according to the standard methods.

\subsection{Protein $C$ and S Analysis}

Functional activity of protein $C$ and S and APCR were assessed on plasma which was collected on tubes containing $0.129 \mathrm{~mol} / \mathrm{L}$ trisodium citrate by auto analyzer ILACL 9000 (Italy) and IL Hemocil Kit (Italy). Normal ranges of protein $\mathrm{C}$ and protein $\mathrm{S}$ activity were considered as 70 $140 \%$ and $63-135 \%$ respectively. Activated protein $C$ resistance more than 2.2 was considered abnormal.

\subsection{Factor V Leiden Analysis}

A $287 \mathrm{bp}$ fragment of the factor $\mathrm{V}$ gene containing the base pair $1691 \mathrm{G}$ A was amplified using polymerase chain reaction (PCR) (16). Digestion of the PCR products containing the wild type, heterozygous and homozygous allele with the restriction enzyme MnII resulted in: 37, 93, $157,130,93,37$; and 157, $130 \mathrm{bp}$ fragments respectively.

\subsection{Prothrombin G20210A Analysis}

A 345 bp fragment of the prothrombin gene containing the base pair 20210G A was amplified using PCR (17). Digestion of the PCR products containing the wild type heterozygous and homozygous allele with the restriction enzyme Hind III resulted in: 345, 322, 23 and 322, 23 bp fragments respectively.

\subsection{Statistical Analysis}


Parand A et al.

Chi-square and Fisher's exact tests were used for comparisons of polymorphism distribution between the groups. Student t-test was used for comparison of quantitative variables between case and control groups. P value $<0.05$ was considered statistically significant.

\section{Results}

The mean age of patients (29.21 \pm 5.9 years) did not differ from that of the controls $(28.75 \pm 5.2$ years $)(P=0.66)$.

Four patients (4.4\%) and one healthy individual (2.3\%) of control group had protein $\mathrm{C}$ deficiency $(\mathrm{P}=0.906)$. Protein $S$ deficiency was detected in $9(10 \%)$ patients. Protein $S$ deficiency was not found in the control group $(\mathrm{OR}=1.11$,
$95 \% \mathrm{CI}=1.03-1.19, \mathrm{P}=0.03)$. The results of screening tests of inherited thrombophilia in case and control groups are shown in Table 1 . The mean functional activity of protein $\mathrm{C}$ and protein $\mathrm{S}$ were not significantly different between the case and control groups $(\mathrm{P}>0.05)$.

There were three homozygous and fifteen heterozygous cases of Factor V Leiden in the patient group. Genotype distribution of FVL was not significantly different between patients and controls $(\mathrm{P}=0.801)$ (Table 2$)$.

There were no homozygous cases of Prothrombin G20210A in either group. Genotype distribution of Prothrombin G20210A was not significantly different between patients and controls $(\mathrm{P}=0.052)$ (Table 3$)$.

Table 1. Comparison of the Results of Screening Tests of Inherited Thrombophilia Between Case and Control Groups

\begin{tabular}{llll}
\hline & Patients $(\mathbf{n}=\mathbf{9 0})$, mean \pm SD & Controls $(\mathbf{n}=\mathbf{4 4})$, mean \pm SD & Pvalue \\
\hline Protein C & $109.7 \pm 45.3$ & $102.3 \pm 42.1$ & 0.366 \\
Protein S & $91.3 \pm 35.4$ & $85.4 \pm 33.1$ & 0.356 \\
APCR & $2.6 \pm 0.2$ & $2.5 \pm 0.5$ & 0.101 \\
\hline
\end{tabular}

Table 2. Distribution of Factor V Leiden in Women With Recurrent Miscarriage and Control Women a

\begin{tabular}{lll}
\hline Genotype & Patients $(\mathbf{n = 9 0})$ & Controls $(\mathbf{n}=\mathbf{4 4})$ \\
\hline Homozygous (AA) & 3 & 0 \\
Heterozygous (AG) & 15 & 6 \\
Wild type (GG) & 72 & 38 \\
\hline a Pvalue $=0.8$ & &
\end{tabular}

Table3. Distribution of Prothrombin G20210A in Women With Recurrent Miscarriage and Control Women a

\begin{tabular}{lll}
\hline Genotype & Patients $(\mathbf{n = 9 0})$ & Controls $(\mathbf{n}=\mathbf{4 4})$ \\
\hline Homozygous (AA) & 0 & 0 \\
Heterozygous (AG) & 2 & 1 \\
Wild type (GG) & 88 & 43 \\
\hline a $_{\text {Pvalue }=0.05}$ & &
\end{tabular}

\section{Discussion}

We found that two common thrombophilic mutations (Factor V Leiden and Prothrombin G20210A) are not significantly associated with the occurrence of recurrent miscarriage.

In the meta-analyses of Robertson et al. (3) and Rey et al. (17) Factor V Leiden and FII G20210A were the only thrombophilic mutations associated with recurrent miscarriage. The prevalence of Factor II G20210A polymorphism in our patients and control group is similar to the integrated results of Rey et al. (17). Factor V Leiden is less common in our patients (only 3 homozygous cases).

As there is regional and ethnic variation in the distribution of thrombophilic polymorphisms, we compared our rates with reports from the same regions. In our study, the frequency of homozygous FVL polymorphism in patients and controls were similar; whereas, Foka et al. (18) reported higher prevalence of the Factor V Leiden in Greek women, despite the similar inclusion criteria and ethnic origin. There was no homozygous case for Prothrombin G20210A polymorphism in our sample, which is similar to the $1 / 150$ rate in women from Chicago, IL, the USA reported by Coulam et al. (11). The rate of homozygosity for Prothrombin G20210A polymorphism in both our patients and controls appears slightly lower than the reported in similar studies in Central European and American populations (10-14\% for patients and 0-16\% for controls); whereas, there are no comparable data from our region. Factor V Leiden and FII G20210A are associated with pregnancy loss in both the first and second trimesters $(19,20)$.

Regarding the association of protein C and S with RPL, similar to the previous studies $(21,22)$, we found a significant association between RPL and protein S deficiency, and a non-significant correlation with protein $C$ deficiency. In our study patients with RPL showed a non-significant higher APC resistance in comparison with healthy women. When analyzing the association between RPL and APC resistance, the APC sensitivity ratio falls progressively throughout normal pregnancy, a change that can occur independently of factor VIII, factor V and protein $S$ levels. Transient APC resistance can be documented during normal gestations, even in women with normal factor V genotype, and APC sensitivity ratios may be further reduced during gestation, potentially explaining the higher prevalence of vascular complications in women with factor $V$ Leiden mutation. Of interest, APC resistance in the absence of factor $\mathrm{V}$ Leiden mutation has also been recently associated with pregnancy $\operatorname{loss}(23,24)$. In a prospective case-control study, APC resistance was the most 
common thrombophilic defect, documented in 39\% of 145 women with pregnancy loss compared to only $3 \%$ of control group, with about a half of the cases attributed to APC resistance without factor V Leiden (OR 1.4, 95\% CI:7.053. 6, P, 0:0001) (23-25). Autoantibodies such as anti-b2 glycoprotein- 1 are one potential mechanism for acquired APC resistance.

Although recent studies demonstrated that factor II G20210A is not associated with an increased risk for RPL as a solitary defect, compared to controls, but they cannot rule out the possibility of factor II G20210A mutation as a risk factor for certain types of $\operatorname{RPL}(26,27)$. Indeed, in a recent study from Italy, Martinelli et al. (28) have documented that both factor V Leiden and factor II G20210A mutations are associated with intrauterine fetal demise (IUFD). Eleven of the 67 women with late loss (16\%) and 13 of the 232 control women (6\%) had either the factor $\mathrm{V}$ or the prothrombin mutation. The relative risks of late fetal loss in carriers of the factor $\mathrm{V}$ and prothrombin mutations were 3.2 (95\% CI, 1.0-10.9) and 3.3 (95\% CI, 1.1-10.3), respectively. Thus, both the factor $\mathrm{V}$ and the prothrombin mutations were associated with an approximate tripling of the risk of late fetal loss.

In most women with inherited thrombophilia pregnancy is uneventful. However, the risks of miscarriage, IUFD, placental abruption, and severe intrauterine growth restriction are increased in carriers of thrombophilia. Why certain women with thrombophilia present with gestational vascular complications is still unknown, but may be related to a combined effect with another inherited or acquired prothrombotic risk either systemic or operating locally at the placental level $(26,27)$.

Fibrin deposition and infarction are found in the placentas of women with thrombophilia and poor gestational outcome. Reports on prophylaxis with low-molecular-weight heparin (LMWH) and unfractionated heparin (UFH), with or without aspirin, suggest a benefit in women with gestational vascular complications and previous poor pregnancy outcome $(26,27)$. Controlled trails presently underway would hopefully define the role of antithrombotics on gestational outcome in women with thrombophilia (27).

Our study was limited due to its small sample size owing to low financial support. The strong point of our study was that we conducted a complete screening for detection of inherited thrombophilia in our patients. With estimated power of $80 \%$, we should evaluate more patients and controls. However, the power of this study was acceptable and calculated as 70\%.

In conclusion, we determined a significant higher frequency of protein $S$ deficiency in patients with RPL compared to healthy controls. But the frequency of protein $\mathrm{C}$ deficiency and the two common thrombophilic mutations (Factor V Leiden and Prothrombin G20210A) were not significantly different between patients with recurrent miscarriage and healthy women. Further studies with larger populations are recommended for better evaluation of FVL and prothrombin mutation in patients with RPL.

\section{Acknowledgements}

This study was performed by a grant from Shiraz University of Medical Sciences. We thank Shirin Parand at the Hematology Research Center for her help with manuscript preparation and editing.

\section{Authors' Contribution}

A. Parand Contributed to data collection. M. karimi contributed to design and concept of study and editing the manuscript. J. Zolghadri Contributed to data collection. M. Nezam drafting the manuscript. AR. Afrasiabi performed the laboratory analysis. S. Haghpanah performed the statistical analysis.

\section{Financial Disclosure}

All authors declare that they have no conflict of interest.

\section{Funding/Support}

This study was performed by a grant from Shiraz University of Medical Sciences.

\section{References}

1. Bennett SA, Bagot CN, Arya R. Pregnancy loss and thrombophilia: the elusive link. Br J Haematol. 2012;157(5):529-42.

2. Tincani A, Cavazzana I, Ziglioli T, Lojacono A, De Angelis V, Meroni P. Complement activation and pregnancy failure. Clin Rev Allergy Immunol.2010;39(3):153-9.

3. Robertson L, Wu O, Langhorne P, Twaddle S, Clark P, Lowe GD, et al. Thrombophilia in pregnancy: a systematic review. Br J Haematol. 2006;132(2):171-96.

4. Hoekema L, Castoldi E, Tans G, Girelli D, Gemmati D, Bernardi F, et al. Functional properties of factor $\mathrm{V}$ and factor Va encoded by the R2-gene. Thromb Haemost. 2001;85(1):75-81.

5. Akar N, Yilmaz E, Akar E, Deda G, Sipahi T. Factor V (His 1299 Arg) in young Turkish patients with cerebral infarct. Haemostasis. 2000;30(3):118-22.

6. Doggen CJ, de Visser MC, Vos HL, Bertina RM, Cats VM, Rosendaal FR. The HR2 haplotype of factor V is not associated with the risk of myocardial infarction. Thromb Haemost. 2000;84(5):815-8.

7. Uchikova EH, Ledjev, II. Changes in haemostasis during normal pregnancy. Eur J Obstet Gynecol Reprod Biol. 2005;119(2):185-8.

8. Ibrahim S, El Dessokiy O. Prevalence of methylenetetrahydrofolate gene (MTHFR) C677T polymorphism among chronic hemodialysis patients and its association with cardiovascular disease a cross-sectional analysis. Clin Exp Nephrol. 2009;13(5):501-7.

9. Haviv YS, Shpichinetsky V, Goldschmidt N, Atta IA, Ben-Yehuda A, Friedman G. The common mutations C677T and A1298C in the human methylenetetrahydrofolate reductase gene are associated with hyperhomocysteinemia and cardiovascular disease in hemodialysis patients. Nephron. 2002;92(1):120-6.

10. Zetterberg H, Regland B, Palmer M, Ricksten A, Palmqvist L, Rymo $\mathrm{L}$, et al. Increased frequency of combined methylenetetrahydrofolate reductase C677T and A1298C mutated alleles in spontaneously aborted embryos. Eur J Hum Genet. 2002;10(2):113-8.

11. Coulam CB, Jeyendran RS, Fishel LA, Roussev R. Multiple throm bophilic gene mutations rather than specific gene mutations are risk factors for recurrent miscarriage. Am J Reprod Immunol. 2006;55(5):360-8.

12. Hohlagschwandtner M, Unfried G, Heinze G, Huber IC, Nagele $\mathrm{F}$, Tempfer C. Combined thrombophilic polymorphisms in 
women with idiopathic recurrent miscarriage. Fertil Steril. 2003;79(5):1141-8

13. Inbal A, Muszbek L. Coagulation factor deficiencies and pregnancy loss. Semin Thromb Hemost. 2003;29(2):171-4.

14. Girolami A, Scandellari R, Lombardi AM, Girolami B, Bortoletto E, Zanon E. Pregnancy and oral contraceptives in factor V deficiency: a study of 22 patients (five homozygotes and 17 heterozygotes) and review of the literature. Haemophilia. 2005;11(1):26-30.

15. Dossenbach-Glaninger A, van Trotsenburg M, Dossenbach M, Oberkanins C, Moritz A, Krugluger W, et al. Plasminogen activator inhibitor $14 \mathrm{G} / 5 \mathrm{G}$ polymorphism and coagulation factor XIII Val34Leu polymorphism: impaired fibrinolysis and early pregnancy loss. Clin Chem. 2003;49(7):1081-6.

16. Hatzaki A, Anagnostopoulou E, Metaxa-Mariatou V, Melissinos C, Philalithis P, Iliadis K, et al. The impact of heterozygosity for the factor V Leiden and factor II G20210A mutations on the risk of thrombosis in Greek patients. Int Angiol. 2003;22(1):79-82.

17. Rey E, Kahn SR, David M, Shrier I. Thrombophilic disorders and fetal loss: a meta-analysis. Lancet. 2003;361(9361):901-8.

18. Foka ZI, Lambropoulos AF, Saravelos H, Karas GB, Karavida A Agorastos T, et al. Factor V leiden and prothrombin G20210A mutations, but not methylenetetrahydrofolate reductase C677T, are associated with recurrent miscarriages. Hum Reprod. 2000;15(2):458-62.

19. Ioannou HV, Mitsis M, Eleftheriou A, Matsagas M, Nousias V Rigopoulos $\mathrm{C}$, et al. The prevalence of factor $\mathrm{V}$ Leiden as a risk factor for venous thromboembolism in the population of NorthWestern Greece. Int Angiol. 2000;19(4):314-8.

20. Zalavras Ch G, Giotopoulou S, Dokou E, Mitsis M, Ioannou HV, Tsaousi C, et al. Prevalence of the G20210A prothrombin gene mutation in Northwestern Greece and association with venous thromboembolism. Int Angiol. 2003;22(1):55-7.

21. Gris JC, Quere I, Monpeyroux F, Mercier E, Ripart-Neveu S, Tail- land ML, et al. Case-control study of the frequency of thrombophilic disorders in couples with late foetal loss and no thrombotic antecedent--the Nimes Obstetricians and Haematologists Study5 (NOHA5). Thromb Haemost. 1999;81(6):891-9.

22. Raziel A, Kornberg Y, Friedler S, Schachter M, Sela BA, Ron-El R. Hypercoagulable thrombophilic defects and hyperhomocysteinemia in patients with recurrent pregnancy loss. Am J Reprod Immunol. 2001;45(2):65-71.

23. Dawood F, Mountford R, Farquharson R, Quenby S. Genetic polymorphisms on the factor $V$ gene in women with recurrent miscarriage and acquired APCR. Hum Reprod. 2007;22(9):2546-53.

24. Donohoe S, Quenby S, Mackie I, Panal G, Farquharson R, Malia R, et al. Fluctuations in levels of antiphospholipid antibodies and increased coagulation activation markers in normal and heparin-treated antiphospholipid syndrome pregnancies. Lupus. 2002;11(1):11-20.

25. Younis JS, Brenner B, Ohel G, Tal J, Lanir N, Ben-Ami M. Activated protein $C$ resistance and factor $V$ Leiden mutation can be associated with first-as well as second-trimester recurrent pregnancy loss. Am J Reprod Immunol. 2000;43(1):31-5.

26. Altintas A, Pasa S, Akdeniz N, Cil T, Yurt M, Ayyildiz O, et al. Factor V Leiden and G20210A prothrombin mutations in patients with recurrent pregnancy loss: data from the southeast of Turkey. Ann Hematol. 2007;86(10):727-31.

27. Resch B, Gallistl S, Kutschera J, Mannhalter C, Muntean W, Mueller WD. Thrombophilic polymorphisms--factor V Leiden, prothrombin G20210A, and methylenetetrahydrofolate reductase C677T mutations--and preterm birth. Wien Klin Wochenschr 2004;116(17-18):622-6.

28. Martinelli I, Taioli E, Cetin I, Marinoni A, Gerosa S, Villa MV, et al. Mutations in coagulation factors in women with unexplained late fetal loss. N Engl J Med. 2000;343(14):1015-8. 